University of Wollongong

Research Online

Faculty of Science - Papers (Archive)

Faculty of Science, Medicine and Health

January 2004

\title{
Molecular dynamics simulations of peptides containing an unnatural amino acid: Dimerization, folding, and protein binding
}

\author{
Haibo Yu \\ University of Wollongong, hyu@uow.edu.au \\ Xavier Daura \\ Universitat Auto ¿noma de Barcelona \\ Wilfred van Gunsteren \\ ETH Zurich
}

Follow this and additional works at: https://ro.uow.edu.au/scipapers

Part of the Life Sciences Commons, Physical Sciences and Mathematics Commons, and the Social and Behavioral Sciences Commons

\section{Recommended Citation}

Yu, Haibo; Daura, Xavier; and van Gunsteren, Wilfred: Molecular dynamics simulations of peptides containing an unnatural amino acid: Dimerization, folding, and protein binding 2004, 116-127. https://ro.uow.edu.au/scipapers/854 


\title{
Molecular dynamics simulations of peptides containing an unnatural amino acid: Dimerization, folding, and protein binding
}

\begin{abstract}
We have performed molecular dynamics (MD) simulations to study the dimerization, folding, and binding to a protein of peptides containing an unnatural amino acid. NMR studies have shown that the substitution of one residue in a tripeptide $\beta$-strand by the unnatural amino acid Hao (5-HO2CCONH-2-MeO-C6H3-CO-NHNH2) modifies the conformational flexibility of the $\beta$-strand and the hydrogen-bonding properties of its two edges: The number of hydrogen-bond donors and acceptors increases at one edge, whereas at the other, they are sterically hindered. In simulations in chloroform, the Hao-containing peptide 9 (i-PrCO-Phe-Hao-Val-NHBu) forms a $\beta$-sheet-like hydrogen-bonded dimer, in good agreement with the available experimental data. Addition of methanol to the solution induces instability of this $\beta$-sheet, as confirmed by the experiments. MD simulations also reproduce the folding of the synthetic peptide 1a (i-PrCO-Hao-Ut-Phe-Ile-Leu-NHMe) into a $\beta$-hairpin-like structure in chloroform. Finally, the Hao-containing peptide, Ac-Ala-Hao-Ala-NHMe, is shown to form a stable complex with the Ras analogue, Rap1 A, in water at room temperature. Together with the available experimental data, these simulation studies indicate that Hao-containing peptides may serve as inhibitors of $\beta$-sheet interactions between proteins.
\end{abstract}

\section{Keywords}

binding, simulations, peptides, molecular, containing, dynamics, unnatural, amino, acid, dimerization, folding, protein, $\mathrm{CMMB}$

\section{Disciplines}

Life Sciences | Physical Sciences and Mathematics | Social and Behavioral Sciences

\section{Publication Details}

Yu, H., Daura, X. \& van Gunsteren, W. (2004). Molecular dynamics simulations of peptides containing an unnatural amino acid: Dimerization, folding, and protein binding. Proteins: Structure, Function, and Bioinformatics, 54 (1), 116-127. 


\title{
Molecular Dynamics Simulations of Peptides Containing an Unnatural Amino Acid: Dimerization, Folding, and Protein Binding
}

\author{
Haibo Yu, Xavier Daura, ${ }^{\dagger}$ and Wilfred F. van Gunsteren* \\ Laboratory of Physical Chemistry, Swiss Federal Institute of Technology Zurich, ETH Hönggerberg, 8093 Zürich, Switzerland
}

\begin{abstract}
We have performed molecular dynamics (MD) simulations to study the dimerization, folding, and binding to a protein of peptides containing an unnatural amino acid. NMR studies have shown that the substitution of one residue in a tripeptide $\beta$-strand by the unnatural amino acid Hao (5-HO ${ }_{2}$ CCONH-2-MeO-C ${ }_{6} \mathrm{H}_{3}-\mathrm{CO}-\mathrm{NHNH2}$ ) modifies the conformational flexibility of the $\beta$-strand and the hydrogen-bonding properties of its two edges: The number of hydrogen-bond donors and acceptors increases at one edge, whereas at the other, they are sterically hindered. In simulations in chloroform, the Hao-containing peptide 9 (i-PrCOPhe-Hao-Val-NHBu) forms a $\beta$-sheet-like hydrogenbonded dimer, in good agreement with the available experimental data. Addition of methanol to the solution induces instability of this $\beta$-sheet, as confirmed by the experiments. MD simulations also reproduce the folding of the synthetic peptide $1 \mathrm{a}$ (i-PrCO-Hao-Ut-Phe-Ile-Leu-NHMe) into a $\beta$-hairpinlike structure in chloroform. Finally, the Haocontaining peptide, Ac-Ala-Hao-Ala-NHMe, is shown to form a stable complex with the Ras analogue, Rap1 A, in water at room temperature. Together with the available experimental data, these simulation studies indicate that Hao-containing peptides may serve as inhibitors of $\beta$-sheet interactions between proteins. Proteins 2004;54:116-127.

๑ 2003 Wiley-Liss, Inc.
\end{abstract}

Key words: computer simulation; molecular dynamics; unnatural amino acid; peptide dimerization; peptide folding; peptideprotein binding

\section{INTRODUCTION}

The formation of $\beta$-sheets involving $\beta$-strands from two proteins constitutes an important form of molecular recognition based on hydrogen bonding between amide groups, and represents a general mode of protein-protein interaction. ${ }^{1}$ Thus, the formation of intermolecular $\beta$-sheets is central to many processes of protein oligomerization, protein aggregation, and peptide-protein binding. For example, HIV-1 protease, an enzyme that plays a critical role in the maturation of HIV (the virus causing AIDS), forms a dimer with $\beta$-sheet interactions between two monomers. ${ }^{2}$ A particularly noteworthy example of $\beta$-sheet formation between different proteins is the binding of the
Ras oncoproteins to their kinase receptors. Ras oncoproteins act as molecular switches that activate the serine/ threonine kinase C-Raf1 (Raf) by binding to its Rasbinding domain (RBD). ${ }^{3,4}$ When oncogenically active Ras exists in the $\beta$-sheet form, this results in a constitutive activation of Ras-mediated signaling events and promotion of aberrant growth in more than $30 \%$ of all human tumors. ${ }^{5}$ Proteins related to neurodegenerative diseases, such as prion disease, ${ }^{6}$ form insoluble aggregates that are rich in $\beta$-sheets. The protease-resistant pathogenic prion protein, $\operatorname{PrP}^{\mathrm{Sc}}$, is rich in $\beta$-sheets and forms amyloid fibrils, whereas its isoform in healthy cells, the cellular prion protein, or $\mathrm{PrP}^{\mathrm{C}}$, has a flexible $\mathrm{N}$-terminal domain and a C-terminal domain that is largely $\alpha$-helical.

The edge of a $\beta$-strand involved in $\beta$-sheet contacts has an alternating array of hydrogen-bond donors and acceptors. Chemical decoys that can mimic these hydrogenbonding edges provide possibilities for developing new drugs that can block, modulate, or mediate $\beta$-sheet interactions between proteins. Peptide derivatives that can block the dimerization of HIV-1 protease ${ }^{7}$ and the self-assembly of $\beta$-amyloids ${ }^{8,9}$ have been reported. Nowick and cowork$\mathrm{ers}^{10-13}$ recently reported the combination of hydrazine, 5-amino-2-methoxybenzoic acid and oxalamide groups with natural peptides that can form a variety of $\beta$-sheet-like structures. The combination of hydrazide, 5-amino-2methoxybenzoic acid and oxalamide groups called Hao can be viewed as an unnatural amino acid that mimics the hydrogen-bonding functionality of one of the edges of a tripeptide $\beta$-strand [Fig. 1(A)]. By NMR studies, Nowick et al. ${ }^{12}$ found that the tripeptide 9 [i-PrCO-Phe-Hao-Val$\mathrm{NHBu}$; Fig. 1(B)] forms a $\beta$-sheet-like hydrogen-bonded dimer in $\mathrm{CDCl}_{3}$ solution (with a dimerization constant of about $10^{6} M^{-1}$ ), whereas the control tripeptide $\mathbf{1 1}$ (i-PrCO-

Grant sponsor: Swiss National Science Foundation; Grant number: 2000-063590.00.

Grant sponsor: National Center of Competence in Research (NCCR) Structural Biology of the Swiss National Science Foundation.

†Present address: Institute of Biotechnology and Biomedicine, Universitat Autònoma de Barcelona E-08193 Bellaterra Spain

*Correspondence to: Wilfred F. van Gunsteren, Laboratory of Physical Chemistry, Swiss Federal Institute of Technology Zurich, ETH Hönggerberg, 8093 Zürich, Switzerland. E-mail: wfvgn@igc. phys.chem.ethz.ch

Received 13 March 2003; Accepted 12 May 2003 
A

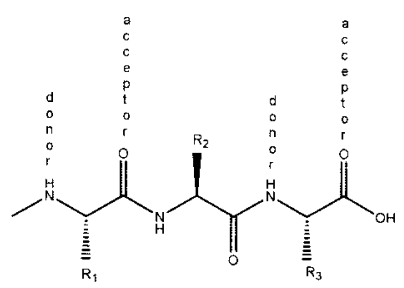<smiles>COC(=O)C(=O)Nc1ccc(O)c(C(=O)NN(C)C)c1</smiles><smiles>CNC(=O)[C@H](N)NC(=O)C(=O)Nc1ccc(O)c(C(=O)NNC(=O)[C@H](C)NC(=O)[O-])c1</smiles>

9<smiles>CNC(=O)C([18OH])NC(=O)[C@H](C)NC(=O)[C@H](C)NC(=O)N(CCN)CCN(P)C(=O)C(=O)Nc1ccc(O)c(C(=O)NNC(=O)C(C)C)c1</smiles>

D

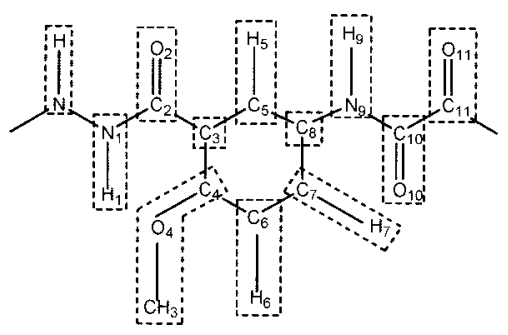

Hao

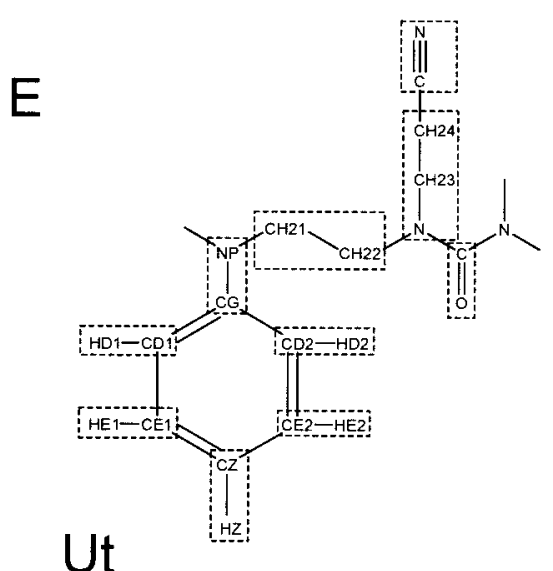

Fig. 1. Chemical formula of a natural tripeptide and the unnatural amino acid Hao (A), the Hao-containing peptide 9: i-PrCO-Phe-Hao-Val-NHBu (B), the Hao-containing peptide 1a: i-PrCO-Hao-Ut-Phe-lle-Leu-NHMe (C), and the atom names for Hao (D) and the urea-based turn fragment Ut (E) are used in the definition of the force-field parameters in Tables II and III. The dashed lines indicate so-called charge groups of the GROMOS96 force field. ${ }^{25,26}$

Phe-Leu-Val-NHBu) showed much weaker self-association, with a dimerization constant between 100 and 200 $M^{-1}$. Addition of $\mathrm{CD}_{3} \mathrm{OD}$, which may compete for hydrogen bonds, to $\mathrm{CDCl}_{3}$ weakens the dimerization of $\mathbf{9}$. In the combination of a Hao-containing strand, a urea-based turn unit (Ut), and a natural peptide strand, the peptide 1a [i-PrCO-Hao-Ut-Phe-Ile-Leu-NHMe; Fig. 1 (C)] was shown to adopt an intramolecular, hydrogen-bonded $\beta$-hairpinlike structure in $\mathrm{CDCl}_{3} .{ }^{11}$ The unnatural amino acid, Hao, confers a preference for a $\beta$-strand conformation to the peptide that contains it, and facilitates its dimerization through $\beta$-sheet interactions. On the other hand, Hao- containing peptides do not induce the formation of multiplestrand $\beta$-sheets, because the aromatic ring of Hao inhibits $\beta$-sheet formation at the other edge of the $\beta$-strand. Therefore, Nowick et al. ${ }^{12}$ anticipated that Hao-containing peptides may also serve as antagonists to block $\beta$-sheet interactions between proteins. They illustrated this through a docking study of Ac-Ala-Hao-Ala-NHMe to the Ras analogue Rap1 A protein.

Molecular dynamics (MD) simulations have been proven successful at reproducing the folding of a number of peptides and have provided insight into some of its principles. ${ }^{14-24}$ Here, we present a series of MD studies of the 
TABLE I. Overview of the MD Simulations of the Dimerization, Folding, and Binding of the Hao-Containing Peptides

\begin{tabular}{|c|c|c|c|c|c|}
\hline Simulation label & Solute Peptides/protein & Solvent & $\begin{array}{c}\text { Number of Solvent } \\
\text { molecules }\end{array}$ & $\begin{array}{c}\text { Temperature } \\
{[\mathrm{K}]}\end{array}$ & $\begin{array}{c}\text { Simulation length } \\
{[\mathrm{ns}]}\end{array}$ \\
\hline $9_{\text {dimer }}$ & 9 dimer & $\mathrm{CHCl}_{3}$ & 962 & 303 & 50 \\
\hline $11_{\text {dimer }}$ & 11 dimer & $\mathrm{CHCl}_{3}$ & 654 & 303 & 50 \\
\hline $9_{\text {dimer }}^{\mathrm{CH}_{3} \mathrm{OH}}$ & 9 dimer & $\mathrm{CH}_{3} \mathrm{OH} / \mathrm{CHCl}_{3}$ & $115 / 1033$ & 303 & 50 \\
\hline $1 \mathrm{a}_{1}$ & $1 \mathrm{a}$ & $\mathrm{CHCl}_{3}$ & 875 & 303 & 100 \\
\hline $1 a_{2}$ & $1 \mathrm{a}$ & $\mathrm{CHCl}_{3}$ & 875 & 303 & 100 \\
\hline $1 a_{3}$ & $1 \mathrm{a}$ & $\mathrm{CHCl}_{3}$ & 875 & 303 & 100 \\
\hline Rap $1 A_{\text {free }}$ & Rap1A & $\mathrm{H}_{2} \mathrm{O}$ & 6618 & 299 & 2 \\
\hline Rap1A & Rap1 A:Ac-Ala-Hao-Ala-NHMe & $\mathrm{H}_{2} \mathrm{O}$ & 6598 & 299 & 2 \\
\hline
\end{tabular}

The three simulations of peptide 1a differ regarding the initial value and strength of the torsional-angle potential energy term for the angle CH22-N-C-N [see Fig. 1(E)]: Simulations $1 \mathrm{a}_{1}$ and $1 \mathrm{a}_{3}$ start with the trans conformation, simulation $\mathrm{la}_{2}$ with the cis conformation. The strengths of the torsional potential energy term are $33.5 \mathrm{~kJ} \mathrm{~mol}^{-1}$ for simulations $1 \mathrm{a}_{1}$ and $1 \mathrm{a}_{2}$, and $7.11 \mathrm{~kJ} \mathrm{~mol}^{-1}$ for simulation $1 \mathrm{a}_{3}$.

dimerization of peptide 9 (i-PrCO-Phe-Hao-Val-NHBu), of the folding of peptide 1a (i-PrCO-Hao-Ut-Phe-Ile-Leu$\mathrm{NHMe}$ ), and of the binding of the peptide Ac-Ala-Hao-AlaNHMe to the Ras analogue Rap1A, using the GROMOS96 package $^{25,26}$ and the GROMOS96 43A1 biomolecular force field. ${ }^{25}$ The simulations are summarized in Table I. Results are compared with the available experimental data, and additional information about the structure and function of Hao-containing peptides is provided.

\section{Simulations}

\section{METHODS}

We carried out the simulations and analyses using the GROMOS96 package of programs. ${ }^{25,26}$

\section{Molecular Model}

The molecular models of the unnatural amino acid residue (Hao) and the urea-based turn unit (Ut) were built analogously to building blocks with the same types of groups in the GROMOS96 $43 \mathrm{~A} 1$ force field. ${ }^{25}$ In this force field, the aliphatic hydrogen atoms are treated, together with the carbon atom to which they are attached as united atoms. ${ }^{26}$ The force field parameters for Hao and Ut are listed in Tables II and III. The protein, Rap1A, and the natural amino acids in the various peptides were modelled according the standard GROMOS96 $43 \mathrm{~A} 1$ force-field parameters. For solvent chloroform, we used a four-center rigid model by Tironi and van Gunsteren, ${ }^{27}$ whereas for solvent water, we used the simple point charge (SPC) model. ${ }^{28}$ After comparing the mixing properties of chloroform and methanol for two different methanol models, ${ }^{25,29}$ we used the standard methanol model of the GROMOS96 $43 \mathrm{~A} 1$ force field ${ }^{25}$ for the simulation of peptide $\mathbf{9}$ in the chloroform/methanol mixture. The simulated systems are listed in Table I.

\section{Simulation Setup}

For each simulation, the solute was placed at the center of a periodic, truncated octahedral box. The minimum distance from any peptide atom to the square box walls was chosen to be at least $1.8 \mathrm{~nm}$ in the initial configuration. We introduced the solvent molecules into the box using a cubic periodic configuration of 216 pre-equilibrated chloroform or water molecules. The minimum distance between the carbon atom of chloroform or the oxygen atom of water and the non-hydrogen atoms of the solute was set to $0.30 \mathrm{~nm}$ and $0.23 \mathrm{~nm}$, respectively. The resulting numbers of solvent molecules in the systems are specified in Table I.

A steepest descent energy minimization of the systems was performed to relax the solute-solvent contacts, whereas the solute atoms were positionally restrained with a harmonic interaction, with a force constant $250 \mathrm{~kJ}$ $\mathrm{mol}^{-1} \mathrm{~nm}^{-2}$. Next, steepest descent energy minimization of the system without restraints was performed to eliminate any residual strain. The energy minimizations were terminated when the energy change per step became smaller than $0.1 \mathrm{~kJ} \mathrm{~mol}^{-1}$.

We obtained the initial coordinates of the dimers of the tripeptides 9 [Fig. 1 (B)] and $\mathbf{1 1}$ by building a model dimer structure. The initial configuration of peptide $\mathbf{1 a}$ [Fig. 1 (C)] was extended, with all the backbone torsional angles set to $180^{\circ}$. The starting structure for the complex of the Ras analogue Rap1A with the Haocontaining peptide was built from the crystal structure of the Ras-binding domain of the c-Raf1 kinase and the Ras analogue, Rap1A [Protein Data Bank (PDB) code 1 gua $^{31}$ ] by modelling the Hao-containing peptide Ac-AlaHao-Ala-NHMe on the complex. All the crystallographically determined water molecules were disregarded. For the dimers of peptides $\mathbf{9}$ and 11, and the complex of Rap1A with Ac-Ala-Hao-Ala-NHMe, 200 ps of MD simulation, with distance restraining of the hydrogen-bonded atoms, was performed to relax the complexes, while maintaining the hydrogen bonds. We started the MD simulations by taking the initial velocities from a Maxwellian distribution at $100 \mathrm{~K}$. Solvent and solute were independently weakly coupled to a temperature bath, with a relaxation time of $0.1 \mathrm{ps} .^{30}$ The systems were also coupled to a pressure bath at $1 \mathrm{~atm}$, with a relaxation time of $0.2 \mathrm{ps}$, and an isothermal compressibility of $1.0 \times$ $10^{-3}\left(\mathrm{~kJ} \mathrm{~mol}^{-1} \mathrm{~nm}^{-3}\right)^{-1}$ for the chloroform simulations, a relaxation time of $0.5 \mathrm{ps}$, and an isothermal compressibility of $0.7513 \times 10^{-3}\left(\mathrm{~kJ} \mathrm{~mol}^{-1} \mathrm{~nm}^{-3}\right)^{-1}$ for the water simulations. Bond lengths were constrained using the SHAKE algorithm, with a geometric tolerance of $10^{-4,31}$ 
TABLE II. Force-Field Parameters for the Unnatural Amino Acid Residue Hao

\begin{tabular}{|c|c|c|c|}
\hline Atom & Description & IAC & Partial charge [e] \\
\hline $\mathrm{N}, \mathrm{N} 1, \mathrm{~N} 9$ & Amide $\mathrm{N}$ & 5 & -0.28 \\
\hline H, H1, H9 & Amide $\mathrm{H}$ & 18 & 0.28 \\
\hline $\mathrm{C} 2, \mathrm{C} 10, \mathrm{C} 11$ & Carbonyl C & 11 & 0.38 \\
\hline $\mathrm{O} 2, \mathrm{O} 10, \mathrm{O} 11$ & Carbonyl O & 1 & -0.38 \\
\hline $\mathrm{C} 3, \mathrm{C} 8$ & Aromatic C & 11 & 0.00 \\
\hline $\mathrm{C} 4$ & Aromatic C & 11 & 0.18 \\
\hline $\mathrm{O} 4$ & Hydroxyl O & 3 & -0.36 \\
\hline CH3 & Aliphatic CH3-group & 14 & 0.18 \\
\hline $\mathrm{C} 5, \mathrm{C} 6, \mathrm{C} 7$ & Aromatic C & 11 & -0.10 \\
\hline $\mathrm{H} 5, \mathrm{H} 6, \mathrm{H} 7$ & Hydrogen bound to $\mathrm{C}$ & 17 & 0.10 \\
\hline$\underline{\text { Bond length }}$ & & $\mathrm{b}_{0}[\mathrm{~nm}]$ & $\mathrm{K}_{\mathrm{b}}\left[10^{6} \mathrm{~kJ} \mathrm{~mol}^{-1} \mathrm{~nm}^{-4}\right]$ \\
\hline $\mathrm{N}-\mathrm{N} 1$ & & 0.133 & 11.8 \\
\hline C10-C11 & & 0.133 & 11.8 \\
\hline Bond angle & & $\theta_{0}$ [degree] & $\mathrm{K}_{\theta}\left[\mathrm{kJ} \mathrm{mol}^{-1}\right]$ \\
\hline H-N-N1, H1-N1-N & & 120.0 & 390 \\
\hline N-N1-C2 & & 117.0 & 635 \\
\hline $\mathrm{O} 2-\mathrm{C} 2-\mathrm{C} 3$ & & 121.0 & 685 \\
\hline $\mathrm{N} 1-\mathrm{C} 2-\mathrm{C} 3$ & & 115.0 & 610 \\
\hline C8-N9-H9 & & 120.0 & 390 \\
\hline C8-N9-C10 & & 123.0 & 415 \\
\hline N9-C10-C11 & & 115.0 & 615 \\
\hline O10-C10-C11, O11-C11-C10 & & 121.0 & 685 \\
\hline Dihedral angle & $\cos (\delta)$ & $\mathrm{m}$ & $\mathrm{K}_{\phi}\left[\mathrm{kJ} \mathrm{mol}^{-1}\right]$ \\
\hline$-\mathrm{N}-\mathrm{N} 1-$ & -1.0 & 2 & 16.7 \\
\hline$-\mathrm{C} 2-\mathrm{C} 3-$ & -1.0 & 2 & 33.5 \\
\hline -C8-N9- & -1.0 & 2 & 7.11 \\
\hline -C10-C11- & -1.0 & 2 & 33.5 \\
\hline Improper dihedral angle & & $\xi_{0}$ [degree] & $\mathrm{K}_{\xi}\left[\mathrm{kJ} \mathrm{mol}^{-1}\right.$ degree $\left.^{-2}\right]$ \\
\hline \multirow{2}{*}{\multicolumn{2}{|c|}{$\begin{array}{l}\text { N-X-N1-H, N1-C2-N-H1, N9-C8-C10-H9 } \\
\text { C2-N1-C3-O2, C10-N9-C11-O10, C11-C10-X-O11 }\end{array}$}} & 0.0 & 0.0510 \\
\hline & & 0.0 & 0.0510 \\
\hline
\end{tabular}

The atom names are defined in Figure 1 (D); the GROMOS96 integer atom code (IAC) defines the Lennard-Jones parameters of the corresponding atoms. Parameters (bond lengths, bond angles, dihedral angles, and improper dihedrals) of carbonyl, amide, benzene, and ether groups (not given) were chosen analogous to GROMOS96 force-field parameters for peptides and noncarbohydrates. ${ }^{25}$ The functional form of the force field is given in van Gunsteren et al. ${ }^{25}$ and Scott et al. ${ }^{26}$

so that the time step for the leapfrog integration could be set to $0.002 \mathrm{ps}$. For the nonbonded interactions, we used a triple-range method with cutoff radii of 0.8 and $1.4 \mathrm{~nm}$. Outside the longer cutoff radius, we used a reaction field approximation, ${ }^{32}$ with a relative dielectric permittivity of 5.0 for chloroform and 78.5 for water. Short-range van der Waals and electrostatic interactions were evaluated every time step with a chargegroup pairlist. Long-range van der Waals and electrostatic interactions between pairs, at a distance longer than $0.8 \mathrm{~nm}$ and shorter than $1.4 \mathrm{~nm}$, were evaluated every fifth time step, at which point the pair list was updated. The center of mass motion of the whole system was removed every 500 time steps, and the trajectory coordinates and energies were saved every $0.5 \mathrm{ps}$ for analysis.

\section{Analysis}

A cluster analysis was performed on all the trajectories from the simulations of peptides $\mathbf{9 , 1 1}$, and $\mathbf{1 a}$ with the use of structures saved at 10-ps intervals. Clustering was performed as described in Daura et $\mathrm{al}^{33}$ by performing a rotational and translational atom-positional least-squares fit for every pair of structures, using all backbone atoms and calculating the corresponding atom-positional rootmean-square difference (RMSD) for the same set of atoms. The similarity criterion used was an RMSD smaller or equal to $0.06 \mathrm{~nm}$ and $0.10 \mathrm{~nm}$, respectively, for the peptides 9/11 and 1a.

We used as a criterion for the occurrence of a hydrogen bond in a given structure a maximum distance of $0.25 \mathrm{~nm}$ 
TABLE III. Force-Field Parameters for the Urea-Based Turn Fragment Ut

\begin{tabular}{|c|c|c|c|}
\hline Atom & Description & IAC & Partial charge [e] \\
\hline $\mathrm{NP}, \mathrm{N}$ & Amide $\mathrm{N}$ & 5 & 0.00 \\
\hline $\mathrm{CG}$ & Aromatic C & 11 & 0.00 \\
\hline CD1, CD2, CE1, CE2, CZ & Aromatic C & 11 & -0.10 \\
\hline HD1, HD2, HE1, HE2, HZ & Hydrogen bound to $\mathrm{C}$ & 17 & 0.10 \\
\hline $\mathrm{CH} 21, \mathrm{CH} 22, \mathrm{CH} 23, \mathrm{CH} 24$ & Aliphatic $\mathrm{CH} 2$-group & 13 & 0.00 \\
\hline $\mathrm{CN}$ & Bare C & 11 & 0.36 \\
\hline $\mathrm{NC}$ & Bare N & 8 & -0.36 \\
\hline $\mathrm{C}$ & Carbonyl C & 11 & 0.38 \\
\hline $\mathrm{O}$ & Carbonyl O & 1 & -0.38 \\
\hline \multicolumn{2}{|l|}{$\underline{\text { Bond length }}$} & $\mathrm{b}_{0}[\mathrm{~nm}]$ & $\mathrm{K}_{\mathrm{b}}\left[10^{6} \mathrm{~kJ} \mathrm{~mol}^{-1} \mathrm{~nm}^{-4}\right]$ \\
\hline \multirow{2}{*}{\multicolumn{2}{|c|}{$\begin{array}{l}\mathrm{CH} 24-\mathrm{CN} \\
\mathrm{CN}-\mathrm{NC}\end{array}$}} & 0.143 & 8.18 \\
\hline & & 0.123 & 16.6 \\
\hline \multicolumn{2}{|l|}{$\underline{B}$ Bond angle } & $\theta_{0}$ [degree] & $\mathrm{K}_{\theta}\left[\mathrm{kJ} \mathrm{mol}^{-1}\right]$ \\
\hline \multicolumn{2}{|c|}{ NP-CG-CD1, NP-CG-CD2, CG-NP-CH21 } & 120.0 & 780 \\
\hline \multicolumn{2}{|c|}{ NP-CH21-CH22, N-CH23-CH24, N-CH22-CH21 } & 109.5 & 520 \\
\hline \multicolumn{2}{|c|}{$\mathrm{CH} 22-\mathrm{N}-\mathrm{CH} 23$} & 116.0 & 620 \\
\hline \multicolumn{2}{|l|}{ CH22-N-C, CH23-N-C } & 122.0 & 700 \\
\hline \multicolumn{2}{|l|}{$\mathrm{CH} 23-\mathrm{CH} 24-\mathrm{CN}$} & 111.0 & 530 \\
\hline \multicolumn{2}{|l|}{ CH24-CN-NC } & 180.0 & 401,244 \\
\hline \multicolumn{2}{|l|}{ Dihedral angle } & $\mathrm{m}$ & $\mathrm{K}_{\phi}\left[\mathrm{kJ} \mathrm{mol}^{-1}\right]$ \\
\hline \multirow{2}{*}{\multicolumn{2}{|c|}{$\begin{array}{l}\text {-NP-CG- } \\
\text {-NP-CH21-, -N-CH22-, -N-CH23- } \\
\end{array}$}} & 2 & 16.7 \\
\hline & & 2 & 1.0 \\
\hline \multicolumn{2}{|l|}{ Improper dihedral angle } & $\xi_{0}$ [degree] & $\mathrm{K}_{\xi}\left[\mathrm{kJ} \mathrm{mol}^{-1}\right.$ degree $\left.^{-2}\right]$ \\
\hline \multicolumn{2}{|c|}{ NP-X-CH21-CG, N-CH22-C-CH23, C-N-N-O } & 0.0 & 0.0510 \\
\hline
\end{tabular}

The atom names are defined in Figure 1 (E). For further explanation, see footnote, Table II.

between the hydrogen atom and the acceptor atom, and a minimum donor-hydrogen-acceptor angle of $135^{\circ}$.

Interproton distances in the simulations were compared to the experimental nuclear Overhauser enhancement (NOE) intensities. We calculated the former by using $r^{-6}$ averaging over the trajectory structures (where $r$ indicates the actual proton-proton distance), which is the method that corresponds best with the time averaging in the NMR experiment in the case of a small molecule that is tumbling fast compared to internal motions. ${ }^{34,35}$ As we mentioned before, in the GROMOS96 43A1 force field, aliphatic hydrogen atoms are not explicitly treated but are part of united atoms. We thus calculated interproton distances involving the aliphatic hydrogen atoms by defining virtual (for $\mathrm{CH}_{1}$ and prochiral $\mathrm{CH}_{2}$ ) and pseudo (for $\mathrm{CH}_{3}$ ) atomic positions for these hydrogen atoms at the time of analysis. $^{26}$ When comparing the experimental NOE-derived distance with the calculated proton-proton distance, pseudoatom corrections involving equivalent or nonstereoassigned protons should be included in the upper-bound NOE-derived distances. ${ }^{36}$

We calculated ${ }^{3} J$-coupling constants from the simulations using the Karplus relation: ${ }^{37}$

$$
{ }^{3} J(H, H)=a \cos ^{2} \theta+b \cos \theta+c .
$$

Two sets of parameters $a, b, c-a=6.40 \mathrm{~Hz}, b=-1.40 \mathrm{~Hz}$, $c=1.90 \mathrm{~Hz}^{38}$ and $a=7.09 \mathrm{~Hz}, b=-1.42 \mathrm{~Hz}, c=1.55$ $\mathrm{Hz}^{39}$ —were used to calculate ${ }^{3} J(\mathrm{HN}, \mathrm{HC})$.

\section{RESULTS AND DISCUSSION Stability of Hao-Containing Peptide Dimers}

${ }^{1} \mathrm{H}$ NMR chemical shift, NOE, and dilution titration studies ${ }^{12}$ indicate that Hao derivative 9 [Fig. 1 (B)] forms a remarkably stable $\beta$-sheet-like hydrogen-bonded dimer in $\mathrm{CDCl}_{3}$ solution, while the control peptide 11 (i-PrCO-PheLeu-Val-NHBu) self associates very weakly. Backbone atom-positional RMSD of the dimer of peptide $\mathbf{9}$ with respect to the initial $\beta$-sheet structure as a function of time is shown in Figure 2 (lower left panel). At $303.15 \mathrm{~K}$, the dimer structure of $\mathbf{9}$ in $\mathrm{CHCl}_{3}$ solution was very stable, with an RMSD value around $0.07 \mathrm{~nm}$ with respect to the model-built $\beta$-sheet dimer structure. With use of as similarity criterion, a backbone-atom RMSD of less than $0.06 \mathrm{~nm}$, cluster analysis shows that $85 \%$ of the trajectory structures belong to the first, most populated cluster. However, some rearrangement of the two chains is observed with respect to the model dimer, especially at the chain termini. The $\beta$-sheet structure is characterized by particular NOEs. ${ }^{40}$ The properly averaged interproton distances from simulation are compared with the NOE intensities ${ }^{12}$ 

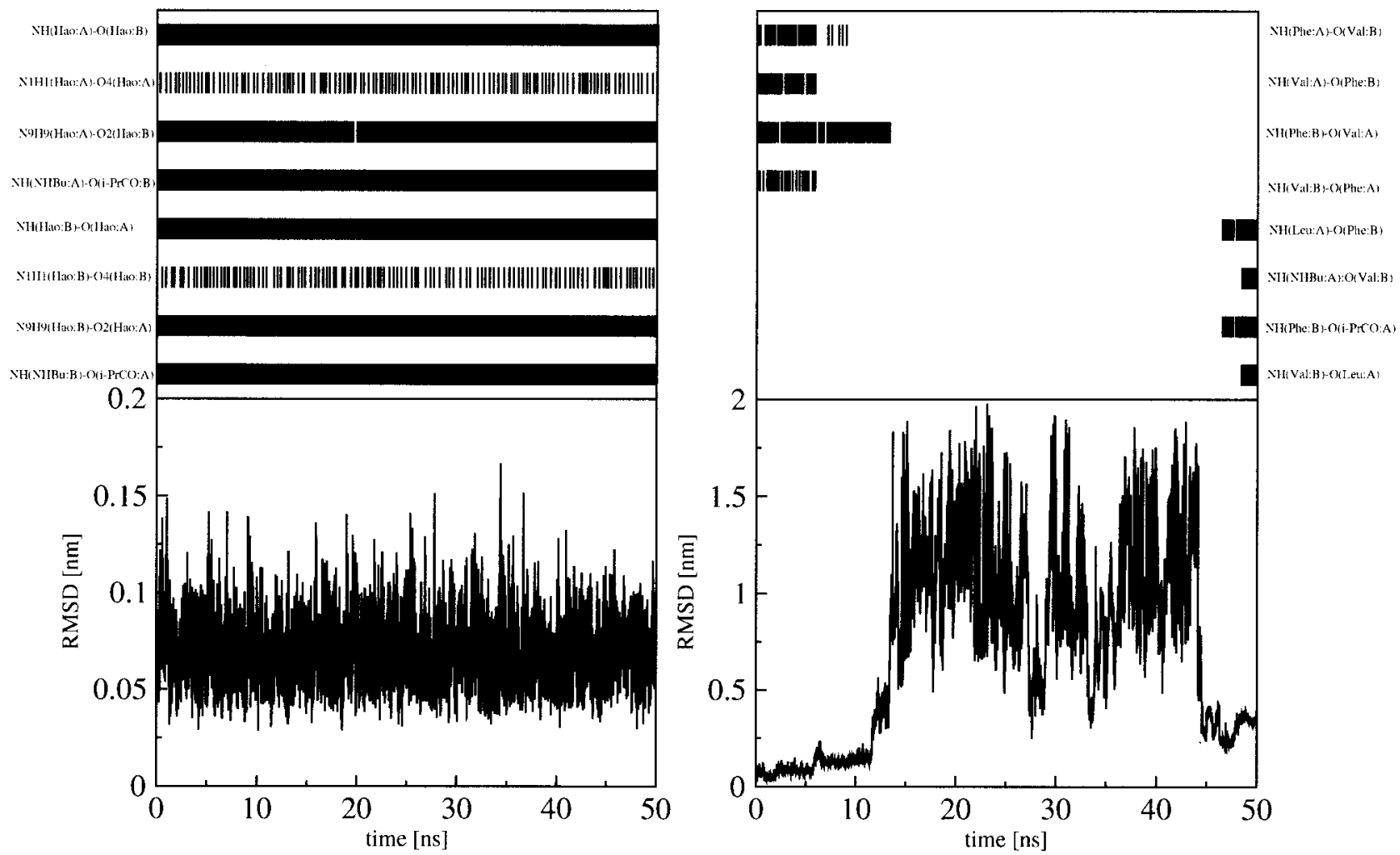

Fig. 2. Upper panels: Occurrences of hydrogen bonds as a function of simulation time for the dimer of peptide 9 (left panel) and of peptide 11 (right panel), both in chloroform. A hydrogen bond is assumed to exist if the hydrogen-acceptor distance is smaller than $0.25 \mathrm{~nm}$ and the donor-hydrogenacceptor angle is larger than $135^{\circ}$. Lower panels: Atom-positional RMSD for the backbone atoms from the starting structure of the dimer of peptide 9 (left panel) and the dimer of peptide 11 (right panel).

TABLE IV. Comparison of Experimental NOE Intensities ${ }^{12}$

\begin{tabular}{|c|c|c|c|c|}
\hline \multicolumn{2}{|c|}{ NOE pair } & \multirow{2}{*}{$\begin{array}{c}\text { Simulated distance } \\
\left\langle r^{-6}\right\rangle^{-1 / 6}[\mathrm{~nm}]\end{array}$} & \multirow{2}{*}{$\begin{array}{c}\text { Pseudoatom } \\
\text { correction }\end{array}$} & \multirow{2}{*}{$\begin{array}{c}\text { Exp. NOE } \\
\text { intensity }\end{array}$} \\
\hline H atom & $\mathrm{H}$ atom & & & \\
\hline H-CA(Phe:A) & H-CA(Val:B) & 0.236 & 0.00 & $\mathrm{~S}$ \\
\hline H-CA(Phe:B) & H-CA(Val:A) & 0.236 & 0.00 & $\mathrm{~S}$ \\
\hline H-CG2(Val:A) & H-CA(Phe:B) & 0.450 & 0.15 & $\mathrm{~W}$ \\
\hline H-CG2(Val:B) & H-CA(Phe:A) & 0.447 & 0.15 & $\mathrm{~W}$ \\
\hline H-CG2(Val:A) & H-CB(Phe:B) & 0.524 & 0.22 & $\mathrm{~W}$ \\
\hline H-CG2(Val:B) & H-CB(Phe:A) & 0.503 & 0.22 & $\mathrm{~W}$ \\
\hline H-CG2(Val:A) & HD1(Phe:B) & 0.452 & 0.35 & $\mathrm{~W}$ \\
\hline H-CG2(Val:B) & HD1(Phe:A) & 0.443 & 0.35 & $\mathrm{~W}$ \\
\hline H9(Hao:A) & H5(Hao:A) & 0.226 & 0.00 & $\mathrm{~S}$ \\
\hline H9(Hao:B) & H5(Hao:B) & 0.226 & 0.00 & $\mathrm{~S}$ \\
\hline H9(Hao:A) & H7(Hao:A) & 0.357 & 0.00 & $\mathrm{~W}$ \\
\hline H9(Hao:B) & H7(Hao:B) & 0.361 & 0.00 & W \\
\hline H-CA(Val:A) & $\mathrm{H}(\mathrm{NHBu}: \mathrm{A})$ & 0.216 & 0.00 & $\mathrm{~S}$ \\
\hline H-CA(Val:B) & $\mathrm{H}(\mathrm{NHBu}: \mathrm{B})$ & 0.217 & 0.00 & $\mathrm{~S}$ \\
\hline H-CA(Val:A) & H(Val:A) & 0.278 & 0.00 & $\mathrm{~W}$ \\
\hline H-CA(Val:B) & H(Val:B) & 0.278 & 0.00 & $\mathrm{~W}$ \\
\hline
\end{tabular}

(S: strong, M: medium, W: weak), with the corresponding $r^{-6}$-averaged hydrogen-hydrogen distances from the MD trajectory for the dimer of peptide 9 in chloroform. The pseudoatom corrections are taken from Fletcher et al. ${ }^{36}$ The two molecules forming the dimer are indicated by A and B.

in Table IV. The strong NOEs between the Phe and Val $\alpha$-protons, and weaker NOEs between the Val $\gamma$ protons and the Phe $\alpha, \beta$, and $\delta$ protons cannot be easily explained by intramolecular contacts, but they are wholly consistent with dimeric structures. The four available ${ }^{3} J$-coupling constants extracted from the NMR spectrum are compared in Table V, with the average coupling constants calculated from the structures of the trajectory at $303.15 \mathrm{~K}$. These coupling constants provide further evidence for a $\beta$-strandlike conformation. ${ }^{40}$ The presence of the interchain hydro- 


\begin{tabular}{|c|c|c|c|c|}
\hline \multicolumn{5}{|c|}{$\begin{array}{c}\text { TABLE V. Comparison of Experimental } \\
{ }^{3} \boldsymbol{J} \text {-Coupling Constants }{ }^{12}\end{array}$} \\
\hline \multicolumn{2}{|c|}{${ }^{3} J$-coupling pair } & \multicolumn{2}{|c|}{${ }^{3} J_{\mathrm{cal}}$} & \multirow{2}{*}{$\frac{{ }^{3} J_{\exp }}{[\mathrm{Hz}]}$} \\
\hline H atom & $\mathrm{H}$ atom & {$[\mathrm{Hz}]$} & $\overline{[\mathrm{Hz}]}$ & \\
\hline H-N(Phe:A) & H-CA(Phe:A) & 8.7 & 9.0 & 8.4 \\
\hline H-N(Phe:B) & H-CA(Phe:B) & 8.7 & 9.0 & 8.4 \\
\hline H-N(Val:A) & H-CA(Val:A) & 7.5 & 7.6 & 9.6 \\
\hline H-N(Val:B) & H-CA(Val:B) & 7.5 & 7.6 & 9.6 \\
\hline
\end{tabular}

${ }^{3} J$-coupling constants are calculated with the Karplus relation, Eq. (1), and averaged over the MD trajectory for the dimer of peptide 9 in chloroform. The two sets of parameters used in the Karplus relation are $a=6.40 \mathrm{~Hz}, b=-1.40 \mathrm{~Hz}, c=1.90 \mathrm{~Hz}^{38}$ (left column) and $a=7.09$ $\mathrm{Hz}, b=-1.42 \mathrm{~Hz}, c=1.55 \mathrm{~Hz}^{39}$ (middle column).

gen bonds NH(Hao:A)-O11(Hao:B), N9H9(Hao:A)-O2(Hao: B), $\mathrm{NH}(\mathrm{NHBu}: \mathrm{A})-\mathrm{O}(\mathrm{i}-\mathrm{PrCO}: \mathrm{B}), \mathrm{NH}(\mathrm{Hao}: \mathrm{B})-\mathrm{O} 11(\mathrm{Hao}: \mathrm{A})$, N9H9(Hao:B)-O2(Hao:A), and $\mathrm{NH}(\mathrm{NHBu}: \mathrm{B})-\mathrm{O}(\mathrm{i}-\mathrm{PrCO}: \mathrm{A})$, which are characteristic for the dimer structure, was inferred from the chemical-shift measurements for the corresponding protons. ${ }^{12}$ These hydrogen bonds were found to be long-lived in the simulation [Fig. 2, upper left panel]. Two intrachain hydrogen bonds, N1H1(Hao:A)-O4(Hao:A) and N1H1(Hao:B)-O4(Hao:B), appear intermittenly [Fig. 2 , upper left panel]. For these hydrogen bonds, the percentages of occurrence in the simulation are listed in Table VI.

In agreement with the experimental data, the dimer structure of the control peptide $\mathbf{1 1}$ turned out to be less stable in the simulation. After $11 \mathrm{~ns}$, the RMSD value increases significantly, and around the same time, the interstrand hydrogen bonds, which are characteristic for the (antiparallel) dimer structure, are lost [Fig. 2, right panels]. Interestingly, after $45 \mathrm{~ns}$, several new hydrogen bonds are formed, and the RMSD from the antiparallel $\beta$-sheet starting structure decreases significantly. The newly formed hydrogen bonds are indicative of a parallel $\beta$-sheet structure.

Experimentally, the addition of the competitive polar solvent $\mathrm{CD}_{3} \mathrm{OD}$ to $\mathrm{CDCl}_{3}$ has been observed to weaken the dimerization of $\mathbf{9}$. Before simulating this ternary mixture, simulations of binary mixtures of $\mathrm{CHCl}_{3}$ and $\mathrm{CH}_{3} \mathrm{OH}$ were performed to investigate the properties of two different models of $\mathrm{CH}_{3} \mathrm{OH}$ : the model available with the standard GROMOS96 force field, ${ }^{26}$ and the more recently developed model by Walser et al. ${ }^{29}$ The mixing enthalpy at $308 \mathrm{~K}$ and the density of the binary mixture at $298 \mathrm{~K}$ as a function of $x_{\mathrm{CH}_{3} \mathrm{OH}}$, the fraction of methanol, are shown in Figure 3, together with the available experimental data. ${ }^{41,42}$ The GROMOS96 model reproduces the mixing enthalpy to within $0.4 \mathrm{~kJ} \mathrm{~mol}^{-1}$, with a deviation in the density of up to $5 \%$ for pure methanol. The newer model yields a very accurate density profile but a deviation of up to $0.7 \mathrm{~kJ}$ $\mathrm{mol}^{-1}$ for the enthalpy of mixing. Because the two models represent the experimental data rather well, either could be used in the simulation of the ternary mixture. But because we were interested in mixtures at low methanol fractions, we chose the standard GROMOS96 $\mathrm{CH}_{3} \mathrm{OH}$ model to study the effect of mixing a polar cosolvent on the stability of the Hao-containing peptide 9 in chloroform.
Figure 4 shows the backbone-atom RMSD of the trajectory structures with respect to the starting antiparallel $\beta$-sheet-like dimer structure. Addition of $10 \% \mathrm{CH}_{3} \mathrm{OH}$ makes the $\mathbf{9}$ dimer less stable, and dissociation and reassociation of the two chains is observed. The polar solvent $\mathrm{CH}_{3} \mathrm{OH}$ can establish hydrogen bonds with the solute, in competition with interstrand hydrogen bonds.

\section{Folding of Peptide 1a into a $\beta$-Hairpin}

For molecule 1a [Fig. $1(\mathrm{C})$ ], we performed three simulations that differ in the starting configurations and the force constants of the torsional angle (CH22-N-C-N) [Fig. 1 (E)] in the urea-based turn unit (Ut). The initial values of this torsional angle in simulations $1 \mathrm{a}_{1}, 1 \mathrm{a}_{2}$, and $1 \mathrm{a}_{3}$ are trans, cis, and trans, respectively, with the force constants $33.5,33.5$, and $7.11 \mathrm{~kJ} \mathrm{~mol}^{-1}$, respectively. In the NMRderived model structure, this torsional angle adopts a cis configuration. The value of this torsional angle as function of simulation time is shown in the three upper panels of Figure 5 for simulations $1 \mathrm{a}_{1}, 1 \mathrm{a}_{2}$, and $1 \mathrm{a}_{3}$, respectively. In the simulations with a higher barrier for the torsional rotation, no transition between the trans and cis conformation was observed during $100 \mathrm{~ns}$ of simulation. To observe cis-trans transitions, the torsional barrier was lowered, resulting in several transitions, with an isomerization time of the torsional angle CH22-N-C-N of about $10 \mathrm{~ns}$. The atom-positional RMSDs from the NMR model structure for the backbone atoms of $\mathbf{1 a}$ in the three simulations are displayed in the lower panels of Figure 5. In all three simulations, folding is observed. In simulation $1 \mathrm{a}_{3}$, both folding and unfolding occur. The $\beta$-hairpin-like structure is formed by a turn stabilized by four hydrogen bonds: $\mathrm{NH}(\mathrm{Hao})-\mathrm{O}(\mathrm{Leu}), \mathrm{NH}(\mathrm{Leu})-\mathrm{O} 2(\mathrm{Hao}), \mathrm{N} 9 \mathrm{H} 9$ (Hao)-O(Phe), and $\mathrm{NH}$ (Phe)-O11(Hao) [Fig. 5, middle panels]. $\mathrm{NH}(\mathrm{Hao})-$ $\mathrm{O}(\mathrm{Leu}), \mathrm{NH}(\mathrm{Leu})-\mathrm{O} 2(\mathrm{Hao})$, and N9H9(Hao)-O(Phe) were found to be long-lived in all three simulations, although out-of-register hydrogen bonding was observed in the first part of simulation $1 \mathrm{a}_{3}$. The $\mathrm{NH}(\mathrm{Phe})-\mathrm{O} 11$ (Hao), which is near the turn, is found to exist only if the torsional angle CH22-N-C-N adopts the cis conformation, as shown in Figure 5 (upper and middle panels).

The 15 NOEs from the rotating-frame Overhauser enhancement spectroscopy (ROESY) spectrum ${ }^{11}$ and the corresponding NOE distances calculated from the simulations, which are indicative of a $\beta$-hairpin-like structure, are listed in Table VII. The one NOE that has experimentally been labeled as strong (s) shows the shortest distance in the simulation. The five NOEs that have experimentally been classified as medium strong (m) are satisfied in all three simulations, except for the HD1-CD1(Ut)-HN(Phe) upper-bound distance, which is only satisfied by the structures from simulations $1 \mathrm{a}_{2}$ and $1 \mathrm{a}_{3}$. This interatomic distance strongly depends on the conformation of the torsional angle $\mathrm{CH} 22-\mathrm{N}-\mathrm{C}-\mathrm{N}$. In the simulation $1 \mathrm{a}_{1}$, this torsional angle stays trans; therefore, the interatomic distance between $\mathrm{HD} 1-\mathrm{CD} 1(\mathrm{Ut})$ and $\mathrm{HN}(\mathrm{Phe})$ is larger than inferred from the experimental data. The 10 NOEs that have experimentally been labeled weak (w) show average distances compatible with the experimental data. 
TABLE VI. Fraction of Hydrogen Bonds in the Simulations of the Dimers of Peptide 9 and 11 in Chloroform

\begin{tabular}{|c|c|c|c|c|c|}
\hline \multicolumn{2}{|c|}{ Dimer of 9} & \multirow[b]{3}{*}{$\%$} & \multirow{2}{*}{\multicolumn{2}{|c|}{$\begin{array}{c}\text { Dimer of } 11 \\
\text { Hydrogen bond }\end{array}$}} & \multirow[b]{3}{*}{$\%$} \\
\hline \multicolumn{2}{|c|}{ Hydrogen bond } & & & & \\
\hline Donor & Acceptor & & Donor & Acceptor & \\
\hline $\mathrm{NH}(\mathrm{Hao}: \mathrm{A})$ & O11(Hao:B) & 95 & NH(Phe:A) & $\mathrm{O}(\mathrm{Val}: \mathrm{B})$ & 8 \\
\hline N1H1(Hao:A) & $\mathrm{O} 4(\mathrm{Hao}: \mathrm{A})$ & 24 & $\mathrm{NH}(\mathrm{Val}: \mathrm{A})$ & $\mathrm{O}(\mathrm{Phe}: \mathrm{B})$ & 7 \\
\hline N9H9(Hao:A) & O2(Hao:B) & 93 & NH(Phe:B) & O(Val:A) & 17 \\
\hline NH(NHBu:A) & $\mathrm{O}(\mathrm{i}-\mathrm{PrCO}: \mathrm{B})$ & 88 & NH(Val:B) & O(Phe:A) & 5 \\
\hline NH(Hao:B) & O11(Наo:A) & 94 & NH(Leu:A) & O(Phe:B) & 6 \\
\hline N1H1(Hao:B) & $\mathrm{O} 4(\mathrm{Hao}: \mathrm{B})$ & 24 & $\mathrm{NH}(\mathrm{NHBu}: \mathrm{A})$ & $\mathrm{O}(\mathrm{Val}: \mathrm{B})$ & 3 \\
\hline N9H9(Hao:B) & O2(Hao:A) & 93 & NH(Phe:B) & $\mathrm{O}(\mathrm{i}-\mathrm{PrCO}: \mathrm{A})$ & 6 \\
\hline NH(NHBu:B) & $\mathrm{O}(\mathrm{i}-\mathrm{PrCO}: \mathrm{A})$ & 88 & $\mathrm{NH}(\mathrm{Val}: \mathrm{B})$ & $\mathrm{O}$ (Leu:A) & 3 \\
\hline
\end{tabular}

A hydrogen bond is assumed to exist if the hydrogen-acceptor distance is smaller than $0.25 \mathrm{~nm}$ and the donor-hydrogen-acceptor angle is larger than $135^{\circ}$. The two molecules forming the dimer are indicated by $\mathrm{A}$ and $\mathrm{B}$.

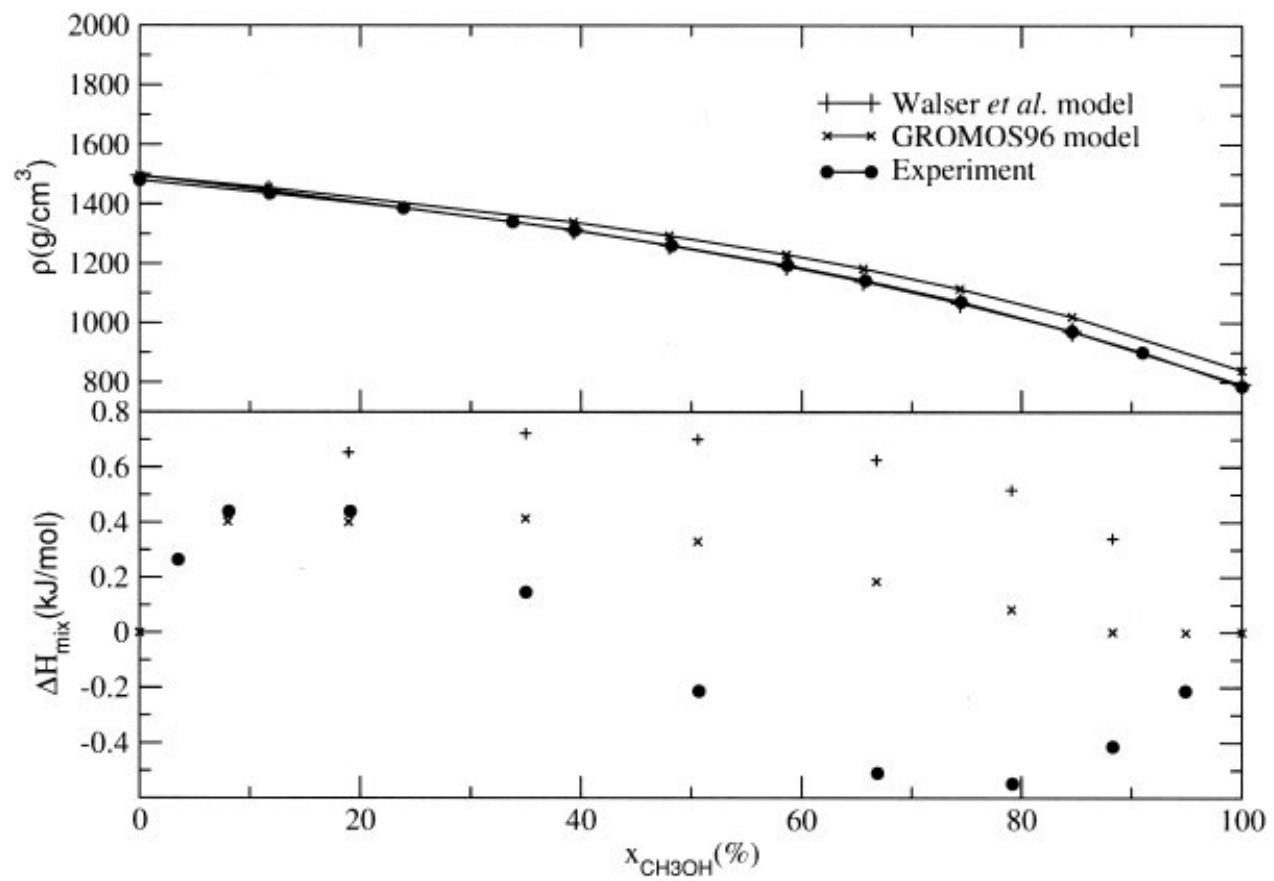

Fig. 3. Comparison of the mixing enthalpy at $308 \mathrm{~K}$ and the density at $298 \mathrm{~K}$ of binary mixtures of $\mathrm{CHCl}_{3}$ and $\mathrm{CH}_{3} \mathrm{OH}$ for two different molecular models (the standard GROMOS96 $43 \mathrm{~A} 1$ force field ${ }^{26}$ and the more recently developed mode ${ }^{29}$ ) as a function of the fraction of methanol $x_{\mathrm{CH}_{3} \mathrm{OH}}$, with experimental data. ${ }^{41,42}$

Figure 6 shows a superposition of the NMR model structure derived with the use of experimental NOE intensities ${ }^{11}$ and the central-member structures from the most populated clusters from simulations $1 \mathrm{a}_{1}, 1 \mathrm{a}_{2}$, and $1 \mathrm{a}_{3}$. The backbone-atom positional RMSD between the central-member structures and the NMR model structure are $0.09 \mathrm{~nm}, 0.06 \mathrm{~nm}$, and $0.07 \mathrm{~nm}$, respectively. The first, most populated, cluster in the three simulations incorporates approximately $84 \%, 91 \%$, and $51 \%$ of the ensemble.

\section{Docking of a Hao-Containing Peptide to the Ras Analogue Rap1A}

MD simulations of both the protein, Rap1A, and the protein-peptide complex, Rap1A:Ac-Ala-Hao-Ala-NHMe, in water were performed to evaluate the stability of the protein-peptide complex. As a measure of structural stability, RMSDs from the starting structure were calculated based on a superposition of all $\mathrm{C}_{\alpha}$ atoms of protein Rap1A. As shown in the lower panel of Figure 7, the overall $\mathrm{C}_{\alpha}$ RMSD of Rap1A stays between 0.15 and 0.20 $\mathrm{nm}$ in both the Rap1A and the Rap1A:Ac-Ala-Hao-Ala$\mathrm{NHMe}$ simulations, indicating a stable protein structure. The intermolecular hydrogen bonds between Rap1A and the Ac-Ala-Hao-Ala-NHMe peptide are shown in the upper panel of Figure 7. Although the hydrogen bond between the C-terminal end of the peptide and a protein sidechain (Asp:38) is lost after $1.6 \mathrm{~ns}$, the backbonebackbone hydrogen bonds between protein and peptide 


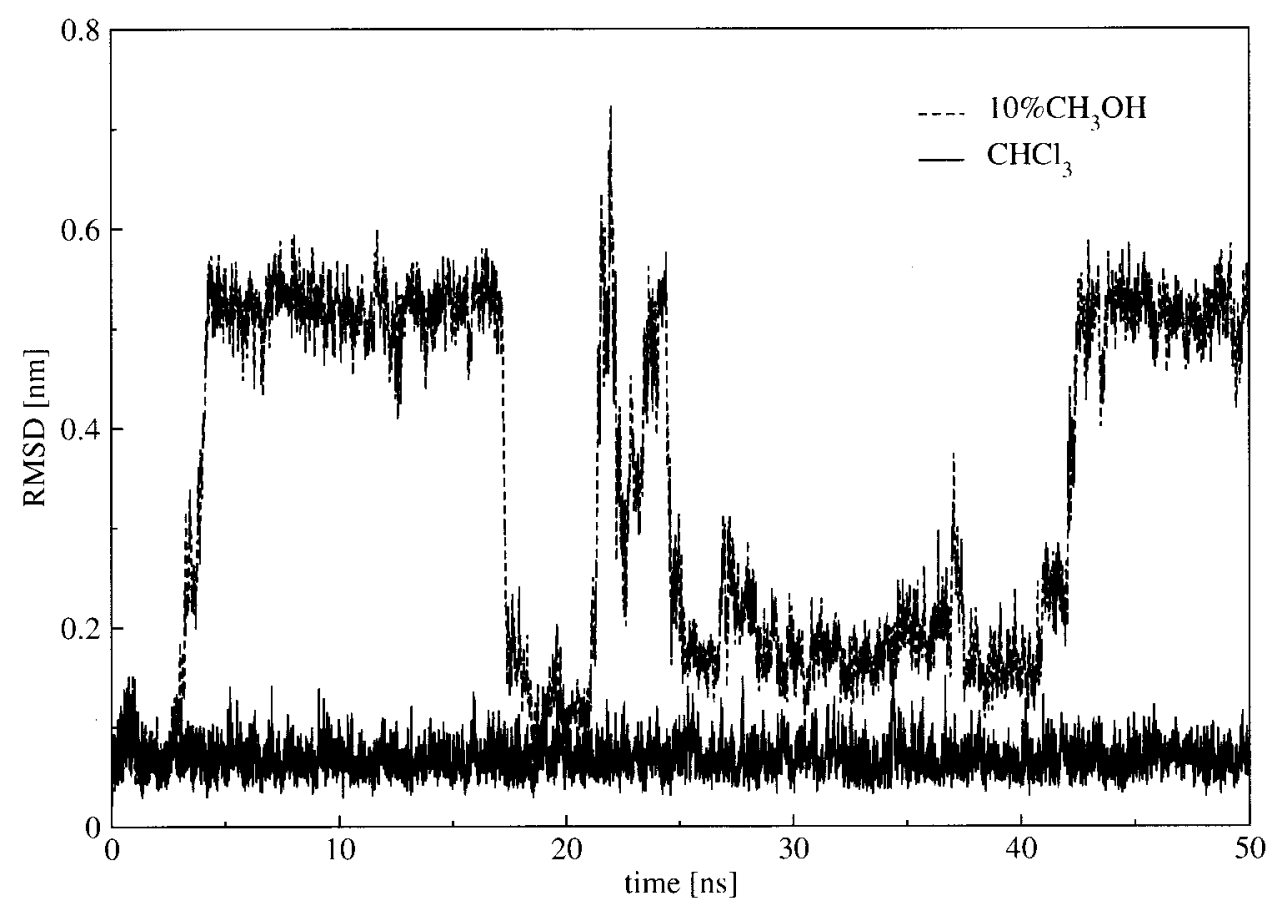

Fig. 4. Atom-positional RMSD for the backbone atoms from the starting structure of the dimer of peptide 9 in pure $\mathrm{CHCl}_{3}$, and in a $10 / 90 \% \mathrm{CH}_{3} \mathrm{OH} / \mathrm{CHCl}_{3}$ solution.

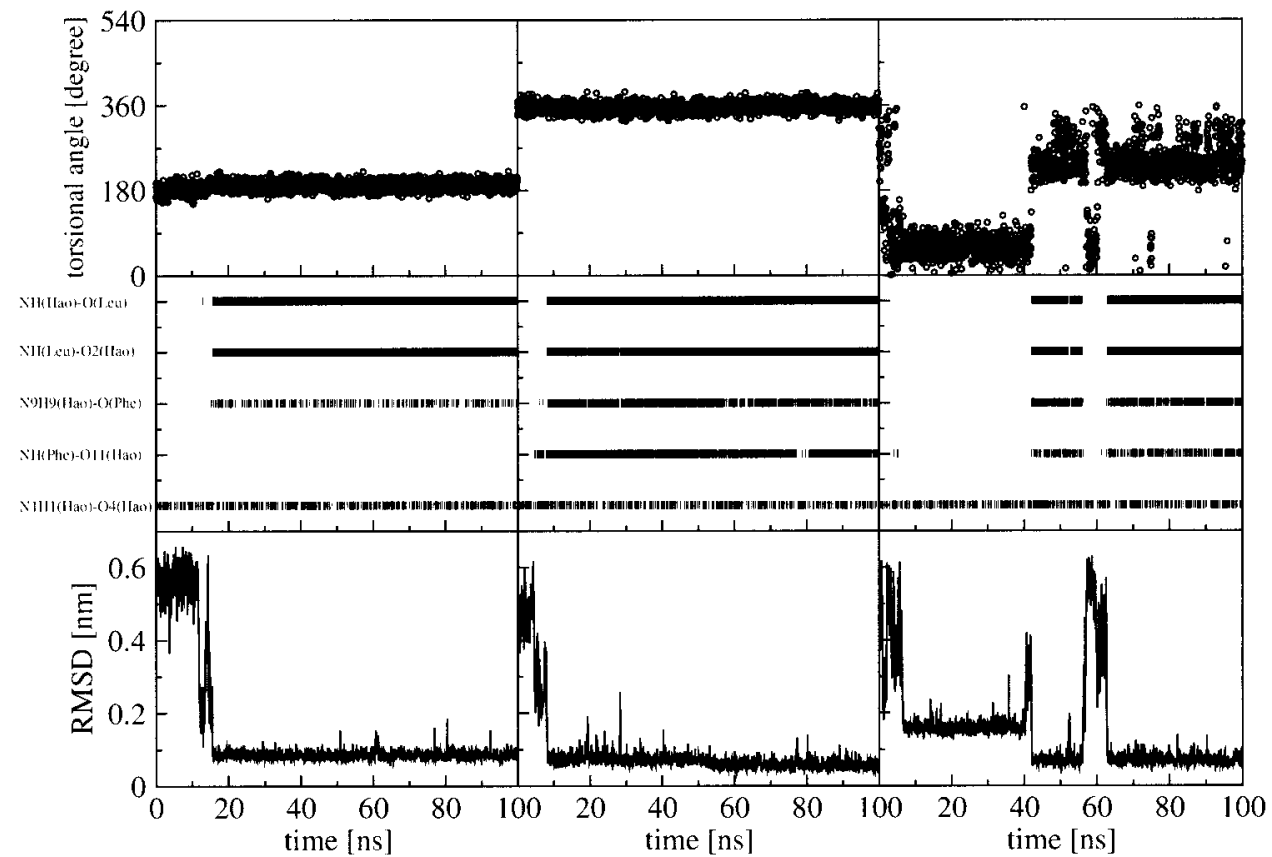

Fig. 5. Upper panels: Dihedral angle CH22-N-C-N as a function of simulation time for the three simulations of the peptide 1a. Middle panels: Occurrence of hydrogen bonds as a function of simulation time for this peptide. A hydrogen bond is assumed to exist if the hydrogen-acceptor distance is smaller than $0.25 \mathrm{~nm}$ and the donor-hydrogen-acceptor angle is larger than $135^{\circ}$. Lower panels: Atom-positional RMSD from the NMR model structure for the backbone atoms of this peptide. The three simulations differ regarding starting conformation and potential energy term for the mentioned dihedral angle (see footnote, Table I).

that form the $\beta$-sheet are stable during the simulation. The complex is stabilized by the interactions between one of the $\beta$-strands of Rap1A and the Hao-containing $\beta$-strand-like structure. Figure 8 shows a snapshot of the Rap1A:Ac-Ala-Hao-Ala-NHMe complex at time $1 \mathrm{~ns}$. The four protein residues that form hydrogen bonds with the peptide are shown explicitly together with the peptide. Indeed, the artificial peptide provides an alter- 
PEPTIDES CONTAINING AN UNNATURAL AMINO ACID

TABLE VII. Comparison of Experimental NOE Intensities ${ }^{11}$

\begin{tabular}{|c|c|c|c|c|c|c|}
\hline \multicolumn{2}{|c|}{ NOE pair } & \multicolumn{3}{|c|}{ Simulated distance $\left\langle r^{-6}\right\rangle^{-1 / 6}$} & \multirow{2}{*}{$\begin{array}{c}\text { Pseudoatom } \\
\text { correction }\end{array}$} & \multirow{2}{*}{$\begin{array}{c}\text { Exp. NOE } \\
\text { intensity }\end{array}$} \\
\hline H atom & $\mathrm{H}$ atom & $1 a_{1}$ & $1 a_{2}$ & $1 a_{3}$ & & \\
\hline H5-C5(Hao) & $\mathrm{H}-\mathrm{CA}(\mathrm{\Pi l})$ & 0.228 & 0.238 & 0.249 & 0.00 & $\mathrm{~S}$ \\
\hline H5-C5(Hao) & H-CG1(Ile) & 0.390 & 0.428 & 0.415 & 0.00 & $\mathrm{~W}$ \\
\hline H5-C5(Hao) & $\mathrm{H}-\mathrm{CD}$ (Ile) & 0.489 & 0.495 & 0.513 & 0.04 & $\mathrm{M}$ \\
\hline H5-C5(Hao) & H-N(Leu) & 0.309 & 0.310 & 0.336 & 0.00 & $\mathrm{~W}$ \\
\hline H-CH(N-ter) & H-CH3(C-ter) & 0.379 & 0.364 & 0.393 & 0.04 & $\mathrm{~W}$ \\
\hline $\mathrm{H}-\mathrm{CH}(\mathrm{N}-$ ter $)$ & $\mathrm{H}-\mathrm{CB}(\mathrm{Leu})$ & 0.382 & 0.398 & 0.428 & 0.00 & $\mathrm{~W}$ \\
\hline $\mathrm{H}-\mathrm{CH}(\mathrm{N}-$ ter $)$ & H-CD1(Leu) & 0.566 & 0.584 & 0.578 & 0.15 & W \\
\hline H-CH(N-ter) & H-CG(Leu) & 0.439 & 0.467 & 0.463 & 0.07 & $\mathrm{~W}$ \\
\hline H-CH31(N-ter) & H-CH3(C-ter) & 0.489 & 0.474 & 0.481 & 0.19 & M \\
\hline H-CH31(N-ter) & H-CG(Leu) & 0.596 & 0.617 & 0.592 & 0.22 & $\mathrm{~W}$ \\
\hline $\mathrm{H}-\mathrm{N}(\mathrm{Hao})$ & H-N(Leu) & 0.324 & 0.316 & 0.349 & 0.00 & $\mathrm{~W}$ \\
\hline H1-N1(Hao) & H-N(Leu) & 0.492 & 0.486 & 0.531 & 0.00 & $\mathrm{~W}$ \\
\hline H9-N9(Наo) & H-N(Phe) & 0.422 & 0.347 & 0.384 & 0.00 & $\mathrm{~W}$ \\
\hline H9-N9(Hao) & HD1-CD1(Ut) & 0.521 & 0.461 & 0.443 & 0.20 & M \\
\hline HD1-CD1(Ut) & $\mathrm{H}-\mathrm{N}(\mathrm{Phe})$ & 0.664 & 0.517 & 0.557 & 0.20 & M \\
\hline
\end{tabular}

(S: strong, M: medium, W: weak), with the corresponding $r^{-6}$ averaged hydrogen-hydrogen distances from the three MD simulations for the peptide 1a in chloroform. The pseudoatom corrections are taken Fletcher et al. ${ }^{36}$ The three simulations differ regarding starting structure and torsional-angle potential energy of the angle $\mathrm{CH} 22-\mathrm{N}$ C-N (see footnote, Table I).

A

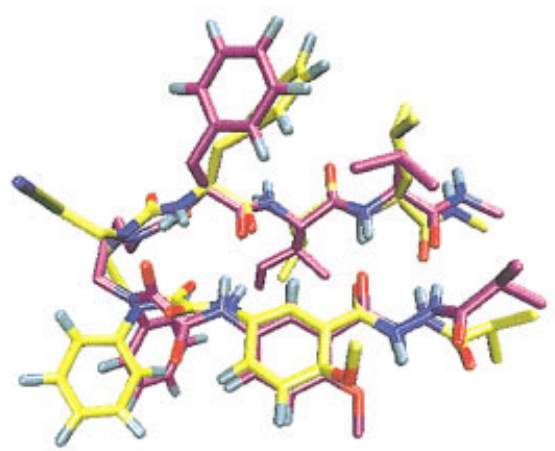

B

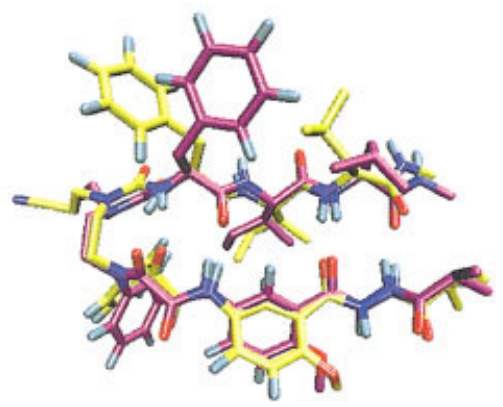

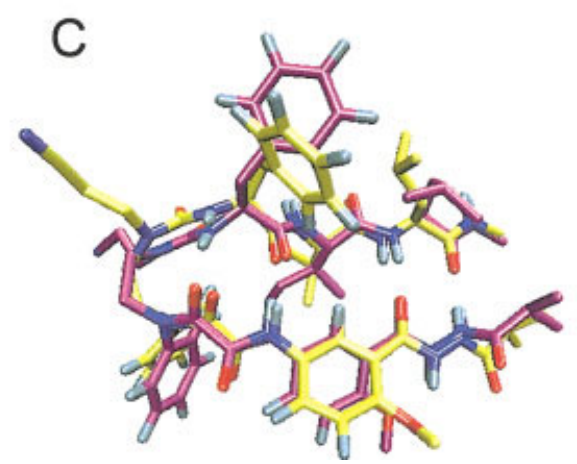

Fig. 6. (A) Superposition of the NMR model structure with the central-member structure of the first, most populated, cluster in the simulation $1 \mathrm{a}_{1}$ (population, 84\%; structure at time, $40.99 \mathrm{~ns} ; 0.09 \mathrm{~nm}$ RMSD). The C atoms are in purple in the NMR model structure, and yellow in the central-member structure of the first cluster. The $\mathrm{N}, \mathrm{O}$, and $\mathrm{H}$ atoms are in blue, red, and cyan, respectively. (B) Superposition of the NMR model structure with the central-member structure of the first, most populated, cluster in the simulation $1 \mathrm{a}_{2}$ (population, $91 \%$; structure at time, $65.27 \mathrm{~ns} ; 0.06 \mathrm{~nm}$ RMSD). (C) Superposition of the NMR model structure with the central-member structure of the first, most populated, cluster in the simulation $1 \mathrm{a}_{3}$ (population, $51 \%$; structure at time, $66.43 \mathrm{~ns} ; 0.07 \mathrm{~nm}$ RMSD). 


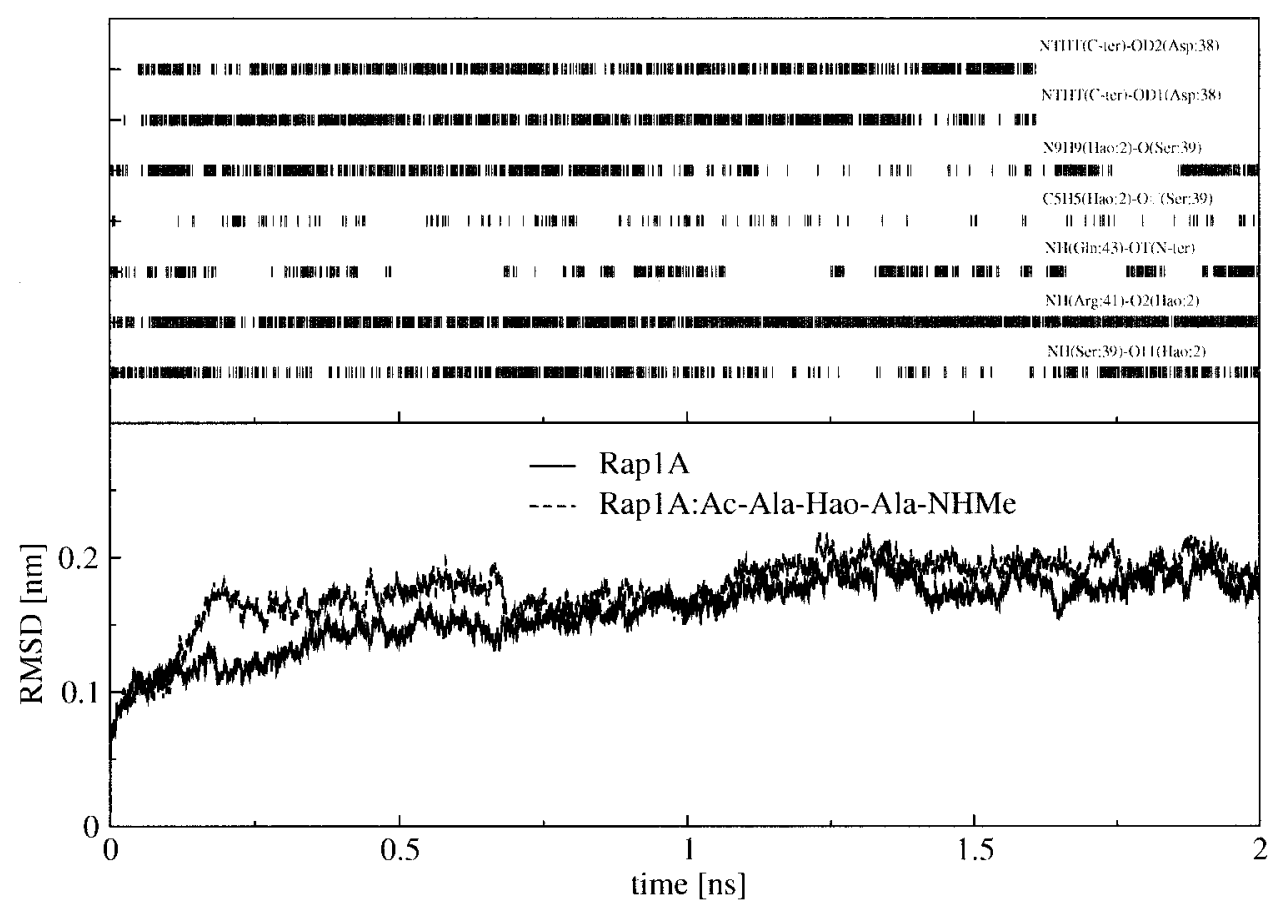

Fig. 7. Upper panel: Occurrence of the hydrogen bonds between the protein Rap1A and peptide Ac-Ala-Hao-Ala-NHMe. A hydrogen bond is assumed to exist if the hydrogen-acceptor distance is smaller than $0.25 \mathrm{~nm}$ and the donor-hydrogen-acceptor angle is larger than $135^{\circ}$. The hydrogen bonds: NTHT(C-ter)OD2(Asp:38), NTHT(C-ter)-OD1(Asp:38), N9H9(Hao:2)-O (Ser:39), C5H5(Hao:2)-OG(Ser:39), NH(Gln:43)OT(N-ter), $\mathrm{NH}($ Arg:41)-O2(Hao:2), and $\mathrm{NH}($ Ser:39)-O11(Hao:2) are present in $60 \%, 55 \%, 52 \%, 17 \%, 35 \%$, $89 \%$, and $52 \%$, respectively, of the configurations. Lower panel: RMSD from the starting structure for all the $\mathrm{C}_{\alpha}$ atoms of the protein Rap1A (PDB code: 1gua).

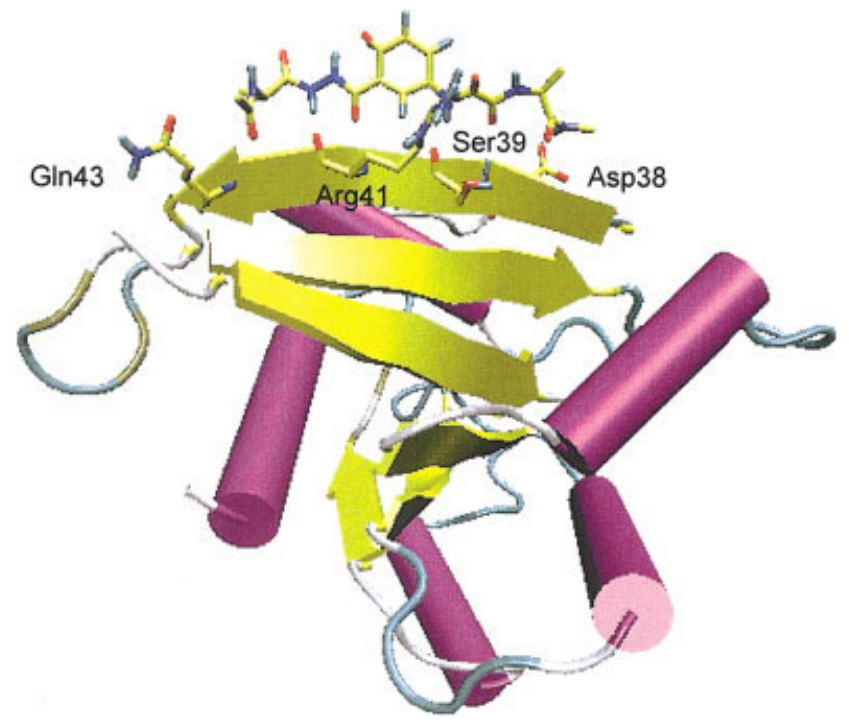

Fig. 8. Snapshot of the Rap1A and the peptide Ac-Ala-Hao-Ala-NHMe in the simulation of the complex in water at $1 \mathrm{~ns}$. The four protein residues-Asp38, Ser39, Arg41, and Gln43-are shown in full, together with the peptide.

nating pattern of hydrogen-bond donors and acceptors that matches that of the target $\beta$-strand in Rap1A.

\section{CONCLUSIONS}

MD simulations, including an explicit treatment of the solvent, have been used to study in atomic detail the dimerization, folding, and binding to a protein surface of peptides containing the unnatural amino acid Hao [Fig. 1(D)]. The peptide 9 [Fig. 1(B)] is found to dimerize strongly in chloroform, as was observed in NMR studies. Compared to the natural tripeptide 11, peptide $\mathbf{9}$ is longer and can form six intermolecular hydrogen bonds. The key structural unit Hao imparts a $\beta$-strand-like conformation to the peptide that contains it and facilitates its dimerization through $\beta$-sheet interactions. Compared to natural amino acids, Hao is conformationally more constrained. Artificial $\beta$-hairpin-like structures, such as that adopted by 1a [Fig. 1 (C)], can be obtained for hybrid peptides consisting of the tripeptide mimic Hao, the turn segment, and a tripeptide part. In the $\beta$-hairpin 1a, Hao serves as a template that organizes the tripeptide part into a $\beta$-hairpin that in turn can form $\beta$-sheet contacts on one edge. In this sense, Hao confers both structure (folding into $\beta$-hairpin-like conformations) and function ( $\beta$-sheet blockage) to the peptides that contain it. Because of the high-energy torsional barrier in the urea-based turn segment, starting from the extended conformation, 1a was not able to fold into the NMR-derived model structure within $100 \mathrm{~ns}$. In the simulation $1 \mathrm{a}_{2}$, starting from the cis conformation of the torsional angle CH22-N-C-N, 1a did fold to the experimentally derived structure, with an RMSD of $0.06 \mathrm{~nm}$ between the central-member structure of the first, most populated, cluster and the NMR model structure. Reduction of the torsional barrier allowed the folding to occur 
within 100 ns. The peptide, Ac-Ala-Hao-Ala-NHMe, was found to form a rather stable complex with the protein, Rap1A. One of the edges of this simple peptide provides an alternating pattern of hydrogen-bond donors and acceptors that finds its counterpart in a $\beta$-strand at the surface of Rap1A, forming an intermolecular $\beta$-sheet. As suggested by Nowick et al., ${ }^{12}$ Hao-containing peptides may hold promise as inhibitors to block $\beta$-sheet interactions between proteins.

\section{ACKNOWLEDGMENTS}

Our thanks to Prof. James S. Nowick for providing the experimental data, and to Dr. Dirk Bakowies for suggestions for deriving force-field parameters.

\section{REFERENCES}

1. Maitra S, Nowick JS. $\beta$-Sheet interactions between proteins. In Greenberg, A, Breneman, CM, Liebman, JF, editors. The amide linkage: Structural significance in chemistry, biochemistry, and materials science. New York: Wiley-VCH; 2000. p 495-518.

2. Wlodawer A, Miller M, Jaskólski M, Sathyanarayana BK, Baldwin E, Weber IT, Selk LM, Clawson L, Schneider J, Kent SBH. Conserved folding in retroviral proteases-crystal-structure of a synthetic HIV-1 protease. Science 1989;245:616-621.

3. Nassar N, Horn G, Herrmann C, Scherer A, McCormick F, Wittinghofer A. The 2.2-angstrom crystal-structure of the Rasbinding domain of the serine threonine kinase C-Raf1 in complex with Rap1A and a GTP analog. Nature 1995;375:554-560.

4. Campbell SL, Khosravi-Far R, Rossman KL, Clark GJ, Der CJ. Increasing complexity of Ras signaling. Oncogene 1998;17: 1395-1413.

5. Barbacid M. Ras genes. Annu Rev Biochem 1987;56:779-827.

6. Prusiner SB. Prions. Proc Natl Acad Sci U S A 1998;95:1336313383.

7. Zutshi R, Franciskovich J, Shultz M, Schweitzer B, Bishop P, Wilson M, Chmielewski J. Targeting the dimerization interface of HIV-1 protease: Inhibition with cross-linked interfacial peptides. J Am Chem Soc 1997;119:4841-4845.

8. Tjernberg LO, Näslund J, Linqvist F, Johansson J, Karlström AR, Thyberg J, Terenius L, Nordstedt C. Arrest of $\beta$-amyloid fibril formation by a pentapeptide ligand. J Biol Chem 1996;271:85458548.

9. Tjernberg LO, Lilliehöök C, Callaway DJE, Näslund J, Hahne S, Thyberg J, Terenius L, Nordstedt C. Controlling amyloid $\beta$-peptide fibril formation with protease-stable ligands. J Biol Chem 1997;272:12601-12605.

10. Nowick JS. Chemical models of protein $\beta$-sheets. Acc Chem Res 1999;32:287-296.

11. Nowick JS, Tsai JH, Bui QCD, Maitra S. A chemical model of a protein $\beta$-sheet dimer. J Am Chem Soc 1999;121:8409-8410.

12. Nowick JS, Chung DM, Maitra K, Maitra S, Stigers KD, Sun Y. An unnatural amino acid that mimics a tripeptide $\beta$-strand and forms $\beta$-sheetlike hydrogen-bonded dimers. J Am Chem Soc 2000;122: 7654-7661.

13. Nowick JS, Lam KS, Khasanova TV, Kemnitzer WE, Maitra S, Mee HT, Liu RW. An unnatural amino acid that induces $\beta$-sheet folding and interaction in peptides. J Am Chem Soc 2002;124:49724973.

14. van Gunsteren WF, Bürgi R, Peter C, Daura X. The key to solving the protein-folding problem lies in an accurate description of the denatured state. Angew Chem Int Ed 2001;40:351-355.

15. Daura X, Jaun B, Seebach D, van Gunsteren WF, Mark AE. Reversible peptide folding in solution by molecular dynamics simulation. J Mol Biol 1998;280:925-932.

16. Daura X, Gademann K, Jaun B, Seebach D, van Gunsteren WF, Mark AE. Peptide folding: When simulation meets experiment. Angew Chem Int Ed 1999;38:236-240.

17. Takano M, Yamato T, Higo J, Suyama A, Nagayama K. Molecular dynamics of a 15-residue poly(L-alanine) in water: Helix formation and energetics. J Am Chem Soc 1999;121:605-612.

18. Peter C, Daura X, van Gunsteren WF. Peptides of aminoxy acids: A molecular dynamics simulation study of conformational equilib- ria under various conditions. J Am Chem Soc 2000;122:74617466.

19. Hummer G, Garcia AE, Garde S. Helix nucleation kinetics from molecular simulations in explicit solvent. Proteins 2001;42:77-84.

20. Daura X, Gademann K, Schäfer H, Jaun B, Seebach D, van Gunsteren WF. The $\beta$-peptide hairpin in solution: Conformational study of a $\beta$-hexapeptide in methanol by NMR spectroscopy and MD simulation. J Am Chem Soc 2001;123:2393-2404.

21. Bürgi R, Daura X, Mark A, Bellanda M, Mammi S, Peggion E, van Gunsteren WF. Folding study of an Aib-rich peptide in DMSO by molecular dynamics simulations. J Peptide Res 2001;57:107-118.

22. Colombo G, Roccatano D, Mark AE. Folding and stability of the three-stranded $\beta$-sheet peptide betanova: Insights from molecular dynamics simulations. Proteins 2002;46:380-392.

23. Wu XW, Wang SM, Brooks BR. Direct observation of the folding and unfolding of a $\beta$-hairpin in explicit water through computer simulation. J Am Chem Soc 2002;124:5282-5283.

24. Glättli A, Daura X, Seebach D, van Gunsteren WF. Can one derive the conformational preference of a beta-peptide from its CD spectrum? J Am Chem Soc 2002;124:12972-12978.

25. van Gunsteren WF, Billeter SR, Eising AA, Hünenberger PH, Krüger P, Mark AE, Scott WRP, Tironi IG. Biomolecular simulation: The GROMOS96 manual and user guide; vdf Hochschulverlag AG an der ETH Zürich and BIOMOS b.v. Zürich: Groningen; 1996.

26. Scott WRP, Hünenberger PH, Tironi IG, Mark AE, Billeter SR, Fennen J, Torda AE, Huber T, Krüger P, van Gunsteren WF. The GROMOS biomolecular simulation program package. J Phys Chem A 1999;103:3596-3607.

27. Tironi IG, van Gunsteren WF. A molecular dynamics simulation study of chloroform. Mol Phys 1994;83:381-403.

28. Berendsen HIC, Postma JPM, van Gunsteren WF, Hermans J. Interaction models for water in relation to protein hydration. In: Pullman B, editor. Intermolecular forces. The Netherlands: Reidel; Dordrecht; 1981. p 331-342.

29. Walser R, Mark AE, van Gunsteren WF, Lauterbach M, Wipff G. The effect of force-field parameters on properties of liquids: Parametrization of a simple three-site model for methanol. J Chem Phys 2000;112:10450-10459.

30. Berendsen HJC, Postma JPM, van Gunsteren WF, DiNola A, Haak JR. Molecular dynamics with coupling to an external bath. J Chem Phys 1984;81:3684-3690.

31. Ryckaert JP, Ciccotti G, Berendsen HJC. Numerical integration of the Cartesian equations of motion of a system with constraints: Molecular dynamics of $n$-alkanes. J Comput Phys 1977;23:327-341.

32. Tironi IG, Sperb R, Smith PE, van Gunsteren WF. A generalized reaction field method for molecular dynamics simulations. J Chem Phys 1995;102:5451-5459.

33. Daura X, van Gunsteren WF, Mark AE. Folding-unfolding thermodynamics of a $\beta$-heptapeptide from equilibrium simulations. Proteins 1999;34:269-280.

34. Tropp J. Dipolar relaxation and nuclear Overhauser effects in nonrigid molecules-the effect of fluctuating inter-nuclear distances. J Chem Phys 1980;72:6035-6043.

35. Daura X, Antes I, van Gunsteren WF, Thiel W, Mark AE. The effect of motional averaging on the calculation of NMR-derived structural properties. Proteins 1999;36:542-555.

36. Fletcher CM, Jones DNM, Diamond R, Neuhaus D. Treatment of NOE constraints involving equivalent or nonstereoassigned protons in calculations of biomacromolecular structures. J Bio NMR 1996;8:292-310.

37. Karplus M. Contact electron-spin coupling of nuclear magnetic moments. J Chem Phys 1959;30:11-15.

38. Pardi A, Billeter M, Wüthrich $K$. Calibration of the angulardependence of the amide proton-C $\alpha$ proton coupling constants, ${ }^{3} \mathrm{JHN} \alpha$, in a globular protein: Use of ${ }^{3} \mathrm{JHN} \alpha$ for identification of helical secondary structure. J Mol Biol 1984;180:741-751.

39. Hu JS, Bax A. Determination of $\Phi$ and $\chi_{1}$ angles in proteins from ${ }^{13} \mathrm{C}-{ }^{13} \mathrm{C}$ three-bond $J$ couplings measured by three-dimensional heteronuclear NMR: How planar is the peptide bond? J Am Chem Soc 1997;119:6360-6368.

40. Wüthrich K. NMR of proteins and nucleic acids. New York: Wiley; 1986. p 125-129.

41. Beggerow G. Landolt-Börnstein: Heats of mixing and solution. Vol. IV/2 of New Series. Berlin: Springer Verlag; 1976.

42. Mikhail SZ, Kimel WR. Densities and viscosities of methanolwater mixtures. J Chem Eng Data 1961;6:533-537. 